\section{An Adaptive Control Approach for Light-emitting Diode Lights Can Reduce the Energy Costs of Supplemental Lighting in Greenhouses}

\author{
Marc W. van Iersel ${ }^{1}$ and David Gianino \\ Department of Horticulture, University of Georgia, 1111 Miller Plant \\ Science Building, Athens, GA 30602
}

Additional index words. dimming, duty cycle, light response curve, photosynthetic photon flux, photosynthesis, pulse width modulation

\begin{abstract}
Supplemental lighting in greenhouses is often needed for year-round production of high-quality crops. However, the electricity needed for supplemental lighting can account for a substantial part of overall production costs. Our objective was to develop more efficient control methods for supplemental lighting, taking advantage of the dimmability of light-emitting diode (LED) grow lights. We compared 14 hours per day of full power supplemental LED lighting to two other treatments: 1) turning the LEDs on, at full power, only when the ambient photosynthetic photon flux (PPF) dropped below a specific threshold, and 2) adjusting the duty cycle of the LEDs so that the LED lights provided only enough supplemental $P P F$ to reach a preset threshold $P P F$. This threshold $P P F$ was adjusted daily from 50 to $250 \mu \mathrm{mol} \cdot \mathrm{m}^{-2} \cdot \mathrm{s}^{-1}$. Turning the LED lights on at full power and off based on a $P P F$ threshold was not practical since this at times resulted in the lights going on and off frequently. Adjusting the duty cycle of the LED lights based on PPF measurements underneath the light bar provided excellent control of $P P F$, with 5-minute averages typically being within $0.2 \mu \mathrm{mol} \cdot \mathrm{m}^{-2} \cdot \mathrm{s}^{-1}$ of the threshold $P P F$. Continuously adjusting the duty cycle of the LED lights reduced electricity use by $20 \%$ to $92 \%$, depending on the $P P F$ threshold and daily light integral (DLI) from sunlight. Simulations based on net photosynthesis $\left(A_{n}\right)-P P F$ response curves indicated that there are large differences among species in how efficiently supplemental $P P F$ stimulates $A_{n}$. When there is little or no sunlight, $A_{n}$ of Heuchera americana is expected to increase more than that of Campanula portenschlagiana when a low level of supplemental light is provided. Conversely, when ambient $P P F>200 \mu \mathrm{mol} \cdot \mathrm{m}^{-2} \cdot \mathrm{s}^{-1}$, supplemental lighting will have little impact on $A_{n}$ of $H$. americana, but can still results in significant increases in $A_{n}$ of $C$. portenschlagiana $\left(1.7\right.$ to $6.1 \mu \mathrm{mol} \cdot \mathrm{m}^{-2} \cdot \mathrm{s}^{-1}$ as supplemental $P P F$ increases from 50 to $\left.250 \mu \mathrm{mol} \cdot \mathrm{m}^{-2} \cdot \mathrm{s}^{-1}\right)$. Adjusting the duty cycle of the LEDs based on $P P F$ levels assures that supplemental light is provided when plants can use that supplemental light most efficiently. Implementing automated duty cycle control of LED grow lights is simple and low cost. This approach can increase the cost effectiveness of supplemental lighting, because of the associated energy savings.
\end{abstract}

The greenhouse industry, including floriculture and greenhouse vegetables, is an important part of U.S. agriculture, with a 2012 farm gate value of $\approx \$ 6.5$ billion (U.S. Department of Agriculture National Agricultural Statistics Service, 2014). Crop production in greenhouses has long been used to overcome natural barriers to crop growth and allow crops to be grown year round and in areas where they otherwise could not (Jensen and Malter, 1995; Woods and Warren, 1988).

Received for publication 23 Sep. 2016. Accepted for publication 31 Oct. 2016 .

We thank the Fred C. Gloeckner Foundation, the American Floral Endowment, the Georgia Centers of Innovation, and the Georgia Research Alliance for financial support for this research.

This work also was supported by the USDA National Institute of Food and Agriculture, Hatch project 1011550.

${ }^{1}$ Corresponding author. E-mail: mvanier@uga.edu. are still the most commonly used lamp for providing supplemental lighting. These lights are expensive to use. Combining the ballast and bulb, a single 400-W HPS light consumes $\approx 465 \mathrm{~W}$ of electrical energy (Nelson, 2003). To provide supplemental light at a $P P F$ of $\approx 85 \mu \mathrm{mol} \cdot \mathrm{m}^{-2} \cdot \mathrm{s}^{-1}$ requires $\approx 1500 \quad 400-\mathrm{W}$ lamps/ha, assuming the lamp provides 1.4 $\mu \mathrm{mol} \cdot \mathrm{J}^{-1}$. If these lamps are used for $16 \mathrm{~h} \cdot \mathrm{d}^{-1}$ and $180 \mathrm{~d} \cdot \mathrm{yr}^{-1}$, at an electrical cost of $\$ 0.12 / \mathrm{kWh}$, the annual electricity cost is $\approx \$ 230,000 /$ ha. That cost accounts for $\approx 30 \%$ of the average annual farm gate value of $\$ 700,000 /$ ha for vegetable greenhouses (U.S. Department of Agriculture National Agricultural Statistics Service, 2014). Clearly, more efficient supplemental lighting will have a major impact on the sustainability and profitability of greenhouses.

There appears to be little past research on optimizing the economic return of supplemental lighting methods for greenhouse production. Heuvelink and Challa (1989) used a crop photosynthesis model to predict assimilate production, assimilate allocation toward salable products, the value of those products, and electricity prices to calculate when supplemental lighting was cost effective. Albright et al. (2000) showed that maintaining a consistent DLI can result in predictable, year-round lettuce production. They developed a set of rules that can be used to control shading and supplemental lighting, based on real-time electricity prices, weather conditions, and location, with the goal of achieving consistent DLIs throughout the year. More recently, Clausen et al. (2015) developed a dynamic control system for supplemental lighting that takes into account real-time electricity pricing, the weather forecast, and photosynthetic responses to light. Part of the rationale behind this dynamic control system is that, because of the nonlinear relationship between $P P F$ and photosynthesis, supplemental light increases photosynthesis more when it is provided when ambient $P P F$ levels are low. Using such a dynamic system to control HPS lights resulted in electricity savings of $\approx 25 \%$ with little effect on production (Clausen et al., 2015; Kjaer et al., 2011).

LEDs provide important advantages over HPS lights. For example, they can provide light with a spectral distribution that can be used efficiently by plants (Bourget, 2008; Goto, 2012; Liu, 2012; Morrow, 2008). It is also possible to manipulate plant morphology or secondary metabolites in crops by using specific spectra (Ouzounis et al., 2015; Stutte, 2015). Although the efficiency of LEDs, expressed in micromoles of $P P F$ produced per Joule of electricity, has long been touted, both Nelson and Bugbee (2014) and Wallace and Both (2016) found that the most efficient HPS and LED lights had similar efficiency $\left(\approx 1.6-1.7 \mu \mathrm{mol} \cdot \mathrm{J}^{-1}\right)$. However, recent improvements in LED technology have resulted in major increases in efficiency with the most efficient LED grow light now at $\approx 2.4$ $\mu \mathrm{mol} \cdot \mathrm{J}^{-1}$ (A.J. Both, personal communication; PLOS ONE, 2016). 
Although LEDs are becoming more efficient and less expensive, LED lighting for large-scale horticultural production is expensive (Bourget, 2008; Pimputkar et al., 2009). The high price of LED lights has slowed adoption of this technology and the cost effectiveness of LEDs for crop production is debated. Nelson and Bugbee (2014) reported that, because the capital costs for LEDs are 5 to $10 \times$ higher than for HPS, LED lights are more expensive per mole of $P P F$ provided. In contrast, Ouzounis et al. (2015) argued that the payback time for LEDs is now realistic, especially if growers take advantage of the ability to control intensity and spectra.

Current LED grow lights do not take full advantage of the capabilities of LEDs. Specifically, the dimmability of LED grow lights has received little attention. The light output from LED lights can be controlled in two different ways. Limiting the current powering the LEDs essentially dims the lights and provides a steady light level, below the maximum light output. Pulse width modulation (PWM) turns LED lights on and off at high frequency $(10,000 \mathrm{~s}$ of times per second). Within each on/off cycle, the fraction of time that the LEDs are on (duty cycle) can be precisely controlled. Reducing the duty cycle creates the perception of dimming, even though in reality, the light is on at full power for a shorter period, followed by a longer off period. Implementation of PWM control is cheap and easy and can be used to adjust the light output from LEDs based on real-time ambient light conditions. Tennessen et al. (1995) showed that leaf photosynthesis of tomato (Solanum lycopersicum) responds to the $P P F$ averaged over the on/off cycle, unless the on/off cycle is excessively long ( $>20 \mathrm{~ms}$ ). Weaver and van Iersel (unpublished data) confirmed that PWM control at high frequency does not affect the light use efficiency or leaf photosynthesis and that leaves respond to the average $P P F$. Tennessen et al. (1995) concluded that photosystems I and II can store a certain amount of excitation energy during the on cycle, which can be used during the subsequent off cycle of the LED light.

Our goal was to develop an automated, adaptive control system for LED grow lights that can prevent the $P P F$ at the canopy level from dropping below a user-defined threshold. We used two different approaches to do so: 1) turn on the LED grow light at full power when the $P P F$ from sunlight drops below a certain threshold $P P F$ and off again when sunlight $P P F$ exceeds the threshold or 2) use a PWM controller to only provide enough supplemental light from LEDs to reach the threshold $P P F$. This adaptive control approach to lighting control should reduce energy use, by providing supplemental light only when needed and, in the case of PWM control, in the amount needed. To quantify reductions in energy use, the two threshold-based lighting control methods were compared with $14 \mathrm{~h} \cdot \mathrm{d}^{-1}$ of continuous, full power supplemental light. Although only one type of LED grow light was tested in this study, the principles can be applied to any LED grow light and control can regardless of whether current or PWM control is used to adjust the light output from the LED grow light.

\section{Materials and Methods}

Setup of LED lights. Three 54-W LED grow light bars $[55 \mathrm{~cm}$ long, PopularGrow, four blue $(450 \mathrm{~nm})$ and 14 red $(640 \mathrm{~nm}) 3-W$ LEDs/bar; Shenzhen Houyi Lighting, Shenzhen, China] were used inside of a glass-covered greenhouse on the Athens campus of the University of Georgia. Although the LED bars are rated for $54 \mathrm{~W}$, they were powered using a $34 \mathrm{~V}$ direct current (DC) power supply and a current of $\approx 0.8 \mathrm{~A}$, thus using $27 \mathrm{~W}$. All three lights were connected to one 34-V DC power supply (DM1-2420 switching power supply; Acme Electric, Menomonee Falls, WI), with PWM control boards (XY-C-1215; PanlongIC, Shandong, China) connected inline between the power supply and the light bars. To measure the $P P F$ underneath the light bars, quantum sensors (Li-190; LI-COR, Lincoln, NE) were placed underneath the middle of each LED bar at a distance of $30 \mathrm{~cm}$. These particular quantum sensors were selected for measurements underneath the light bars, because their good spectral response assures accurate data under lights with different spectra (i.e., sunlight and LEDs). The $P P F$ of incoming sunlight was measured using a fourth quantum sensor (SQ-110; Apogee Instruments, Logan, UT). All four quantum sensors were calibrated under sunlight against a common standard (Utah State University, 2016). The four quantum sensors were connected to a measurement and control datalogger (CR1000; Campbell Scientific, Logan, UT). An analog output module (SDM-AO4, Campbell Scientific) was used to provide precisely controlled 0 to $5-\mathrm{V}$ DC signals from the datalogger to the PWM control boards. This analog output module can provide four independent, precisely controlled DC voltage signals to external devices. The PWM control boards controlled the light output from the LEDs, based on the voltage signal provided by the analog output module. Providing a $0-\mathrm{V}$ DC signal to the input on the PWM board resulted in a duty cycle of 0 (no power) and the duty cycle increased linearly as the provided voltage signal increased to $5-\mathrm{V}$ DC. The frequency of the on/off cycles was $15 \mathrm{kHz}$. The datalogger measured the quantum sensors and adjusted the voltage signal from the analog output module every second. Data were averaged and stored in the datalogger's memory every $5 \mathrm{~min}$. To prevent shading of the quantum sensors by the light bars, the light bars were oriented east-west. However, the quantum sensors were shaded at times by the greenhouse structure and the control system reacted to this shading.

Treatments. Three different approaches to supplemental lighting were compared in this study: 1) $14 \mathrm{~h}$ of supplemental lighting per day from 600 to 2000 , with the LED light bar at full power during the entire period (control), 2) for $14 \mathrm{~h} \cdot \mathrm{d}^{-1}$, the LED light bar was turned on at full power whenever the $P P F$ from ambient sunlight dropped below a specific threshold value and the light remained on until the $P P F$ from sunlight was above the threshold again ( $P P F$ control), and 3 ) for 14 $\mathrm{h} \cdot \mathrm{d}^{-1}$, PWM control of the power supply to the LED was used to provide just enough light to reach the $P P F$ threshold (PWM control, Fig. 1). The duty cycle was adjusted once a second, based on the ratio between the threshold $P P F$ and the measured $P P F$ underneath the LED light bar, that is, if the measured $P P F$ was $10 \%$ below the threshold $P P F$, the duty cycle was increased by $10 \%$. In the latter two treatments, the LED light was off when the $P P F$ was above the threshold.

Although the LED bars in the first two treatments could in principle have been controlled with a relay, we used PWM boards in all three treatments to assure that the different lighting control treatments were fully comparable. The different lighting approaches were tested over a $20-\mathrm{d}$ period in January, 2016, when ambient light levels were relatively low (DLIs from sunlight ranged from 1.4 to $9.5 \mathrm{~mol} \cdot \mathrm{m}^{-2} \cdot \mathrm{d}^{-1}$ ).

Fig. 1. Diagram of the adapative lighting control system. A datalogger and control system uses a quantum sensor to measure the photosynthetic photon flux $(P P F)$ underneath the LED light. Based on the measured $P P F$, the datalogger adjusts a 0 to $5 \mathrm{~V}$-DC signal that is sent to a duty cycle (or pulse width modulation) control board. If the measured $P P F$ is lower than the programmed $P P F$ threshold, the duty cycle (fraction of time the LED light is energized during a very short on/off cycle) is increased and vice versa.

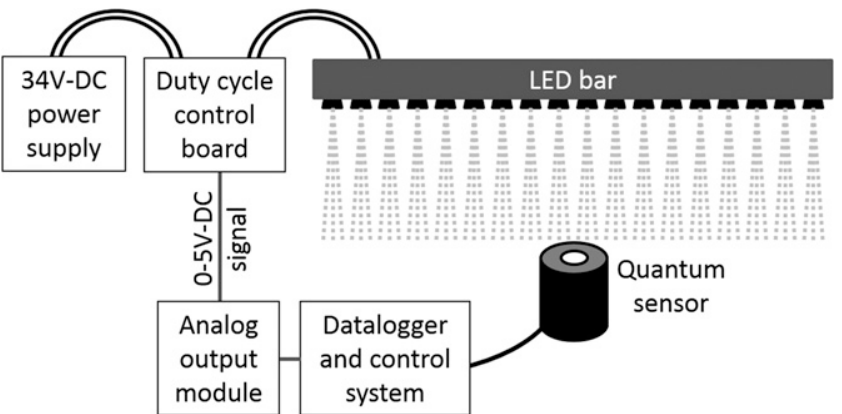


During this 20-d period, the threshold $P P F$ was changed daily, ranging from 50 to 250 $\mu \mathrm{mol} \cdot \mathrm{m}^{-2} \cdot \mathrm{s}^{-1}$, in $50 \mu \mathrm{mol} \cdot \mathrm{m}^{-2} \cdot \mathrm{s}^{-1}$ steps. Each of the five $P P F$ thresholds was maintained for $14 \mathrm{~h} \cdot \mathrm{d}^{-1}$ on four separate days. However, the LED light bars could only provide a maximum of $\approx 225 \mu \mathrm{mol} \cdot \mathrm{m}^{-2} \cdot \mathrm{s}^{-1}$ of $P P F$ and was thus not able to maintain a threshold $P P F$ of $250 \mu \mathrm{mol} \cdot \mathrm{m}^{-2} \cdot \mathrm{s}^{-1}$ when sunlight provided less than $25 \mu \mathrm{mol} \cdot \mathrm{m}^{-2} \cdot \mathrm{s}^{-1}$ of $P P F$.

Data analysis. Data were analyzed using multiple regression models (SigmaPlot 11; Systat Software, San Jose, CA), with $P=$ 0.05 considered to be statistically significant. Multiple regression was used to quantify the relationships among the instantaneous duty cycle, $P P F$ from sunlight, and $P P F$ threshold. Since the relationship between the duty cycle and $P P F$ from sunlight became clearly nonlinear at very low duty cycles $(<0.05)$ and the LED bars were not able to provide 250 $\mu \mathrm{mol} \cdot \mathrm{m}^{-2} \cdot \mathrm{s}^{-1}$ of $P P F$, only data with duty cycles between 0.05 and 0.95 were included in this analysis. For this analysis, only one day of data at each $P P F$ threshold was used, because the relationship was essentially identical for different days with the same $P P F$ threshold. For each $P P F$ threshold, the day with the lowest DLI from sunlight ( $\left.\mathrm{DLI}_{\text {sun }}\right)$ was selected, because that resulted in more supplemental lighting, and thus the most data points.

Multiple regression was also used to determine the relationship among daily average duty cycle, $\mathrm{DLI}_{\text {sun }}$, and $P P F$ threshold and among the DLI underneath the light bar, $\mathrm{DLI}_{\text {sun }}$, and the average daily duty cycle.

Simulation of the effects on photosynthesis. To quantify the relationship among sunlight, supplement light, and $\mathrm{A}_{\mathrm{n}}$, we used $\mathrm{A}_{\mathrm{n}}-P P F$ response curves for $H$. americana 'Dale's Strain' (data derived from Garland et al., 2012) and C. portenschlagiana 'Blue Get Mee' (data from Kjaer et al., 2011). Heuchera americana 'Dale's Strain' was grown at an average DLI of $7.5 \mathrm{~mol} \cdot \mathrm{m}^{-2} \cdot \mathrm{d}^{-1}$ and ambient $\mathrm{CO}_{2}$ concentrations. Campanula portenschlagiana was grown under long day conditions (19-h photoperiod) with supplemental light from high-pressure sodium lamps at a $P P F$ of $\approx 60 \mu \mathrm{mol} \cdot \mathrm{m}^{-2} \cdot \mathrm{s}^{-1}$ whenever ambient PPF dropped below $198 \mu \mathrm{mol} \cdot \mathrm{m}^{-2} \cdot \mathrm{s}^{-1}$. These two data sets were used because of the different $\mathrm{A}_{\mathrm{n}}-P P F$ response curves of these two species. Heuchera americana has a higher $\mathrm{A}_{\mathrm{n}}$ at low PPF $\left(<200 \mu \mathrm{mol} \cdot \mathrm{m}^{-2} \cdot \mathrm{s}^{-1}\right)$ than $C$. portenschlagiana, but a much lower maximum $\mathrm{A}_{\mathrm{n}}\left(10.4 \mu \mathrm{mol} \cdot \mathrm{m}^{-2} \cdot \mathrm{s}^{-1}\right.$ vs. $24.6 \mu \mathrm{mol} \cdot \mathrm{m}^{-2} \cdot \mathrm{s}^{-1}$ for C. portenschlagiana).

To calculate the effect of supplemental lighting on leaf $\mathrm{A}_{\mathrm{n}}$, a three parameter, asymptotic rise to a maximum curve was fitted to the $\mathrm{A}_{\mathrm{n}}-P P F$ data from Garland et al. (2012) and Kjaer et al. (2011), which resulted in excellent curve fits $\left(R^{2}>0.98\right)$. The resulting regression curves were then used to estimate the increase in $A_{n}$ as different amounts of supplemental light $\left(50-250 \mu \mathrm{mol} \cdot \mathrm{m}^{-2} \cdot \mathrm{s}^{-1}\right)$ were added to varying levels of sunlight, ranging from 0 to $\left.250 \mu \mathrm{mol} \cdot \mathrm{m}^{-2} \cdot \mathrm{s}^{-1}\right)$.

\section{Results}

PWM control of LED grow lights. Although using PWM control to adjust the light output from the LED light bars, the control system was able to quickly and accurately adjust the duty cycle of the LED bar to achieve the desired $P P F$ level underneath the light bar. During periods when supplemental light was needed, the system responded quickly to sudden changes in ambient $P P F$; the measured $P P F$ underneath the light bar typically was within $2 \mu \mathrm{mol} \cdot \mathrm{m}^{-2} \cdot \mathrm{s}^{-1}$ of the $P P F$ threshold after five duty cycle adjustments (i.e., within $5 \mathrm{~s}$ ). When averaged over 5-min periods, $P P F$ levels typically were within $0.2 \mu \mathrm{mol} \cdot \mathrm{m}^{-2} \cdot \mathrm{s}^{-1}$ of the threshold $P P F$ during periods that supplemental light was needed (Fig. 2). To maintain a threshold $P P F$ of $50 \mu \mathrm{mol} \cdot \mathrm{m}^{-2} \cdot \mathrm{s}^{-1}$, the duty cycle was maintained at $\approx 0.23$ (or $23 \%$ of full power) before sunrise and after sunset. As the $P P F$ from sunlight gradually increased during sunrise, and decreased during sunset, the duty cycle was adjusted accordingly. Since sunlight during most of the photoperiod was above $50 \mu \mathrm{mol} \cdot \mathrm{m}^{-2} \cdot \mathrm{s}^{-1}$, supplemental lighting was rarely needed to prevent $P P F$ from dropping below $50 \mu \mathrm{mol} \cdot \mathrm{m}^{-2} \cdot \mathrm{s}^{-1}$ (other than during sunrise and sunset). This resulted in a duty cycle of 0 during much of the day (Fig. 2). Also note that on a relatively sunny January day $\left(\right.$ DLI $\left._{\text {sun }}=6.2 \mathrm{~mol} \cdot \mathrm{m}^{-2} \cdot \mathrm{d}^{-1}\right)$, the $P P F$ from sunlight and the $P P F$ underneath the light bar differed significantly at times when no supplemental light was provided. The direct sunlight resulted in distinct shading of the quantum sensors by the greenhouse structure, which affected the different quantum sensors at different times. On an overcast January day $\left(\mathrm{DLI}_{\text {sun }}=3.3 \mathrm{~mol} \cdot \mathrm{m}^{-2} \cdot \mathrm{d}^{-1}\right)$, the sunlight was diffuse and did not create distinct shadows. As a result, the $P P F$ from sunlight and underneath the LED light were similar when the duty cycle of the LED bar was 0 (Fig. 2).

Since the light bars were only able to provide a $P P F$ of $\approx 225 \mu \mathrm{mol} \cdot \mathrm{m}^{-2} \cdot \mathrm{s}^{-1}$, the $P P F$ underneath the LED bar was below the $250 \mu \mathrm{mol} \cdot \mathrm{m}^{-2} \cdot \mathrm{s}^{-1}$ threshold during early morning and late afternoon (Fig. 2). When sunlight provided more than $25 \mu \mathrm{mol} \cdot \mathrm{m}^{-2} \cdot \mathrm{s}^{-1}$ of $P P F$, the duty cycle dropped below 1 and the adaptive control system successfully maintained a $P P F$ of $250 \mu \mathrm{mol} \cdot \mathrm{m}^{-2} \cdot \mathrm{s}^{-1}$. Pulse width modulation control was able to maintain 100 , 150 , and $200 \mu \mathrm{mol} \cdot \mathrm{m}^{-2} \cdot \mathrm{s}^{-1}$ threshold $P P F$ levels accurately as well (data not shown).

Regardless of the threshold $P P F$, there was a strong negative correlation between the duty cycle of the LED bars and the $P P F$ provided by sunlight, but this relationship depended on the threshold $P P F$ (Fig. 3). Not surprisingly, with the same amount of $P P F$ from sunlight, higher duty cycles were required to achieve higher $P P F$ levels. Every $50 \mu \mathrm{mol} \cdot \mathrm{m}^{-2} \cdot \mathrm{s}^{-1}$ increase in target $P P F$ required the duty cycle to be increased by $\approx 0.2$. When the $P P F$ from sunlight was close to or slightly above the target $P P F$, the relationship between the duty cycle and $P P F$ was no longer linear. This is the result of averaging 300 data points over 5-min intervals during a 5-min period, the average $P P F$ may well be slightly over the $P P F$ threshold, even though the supplemental lighting may be needed at times during that 5-min

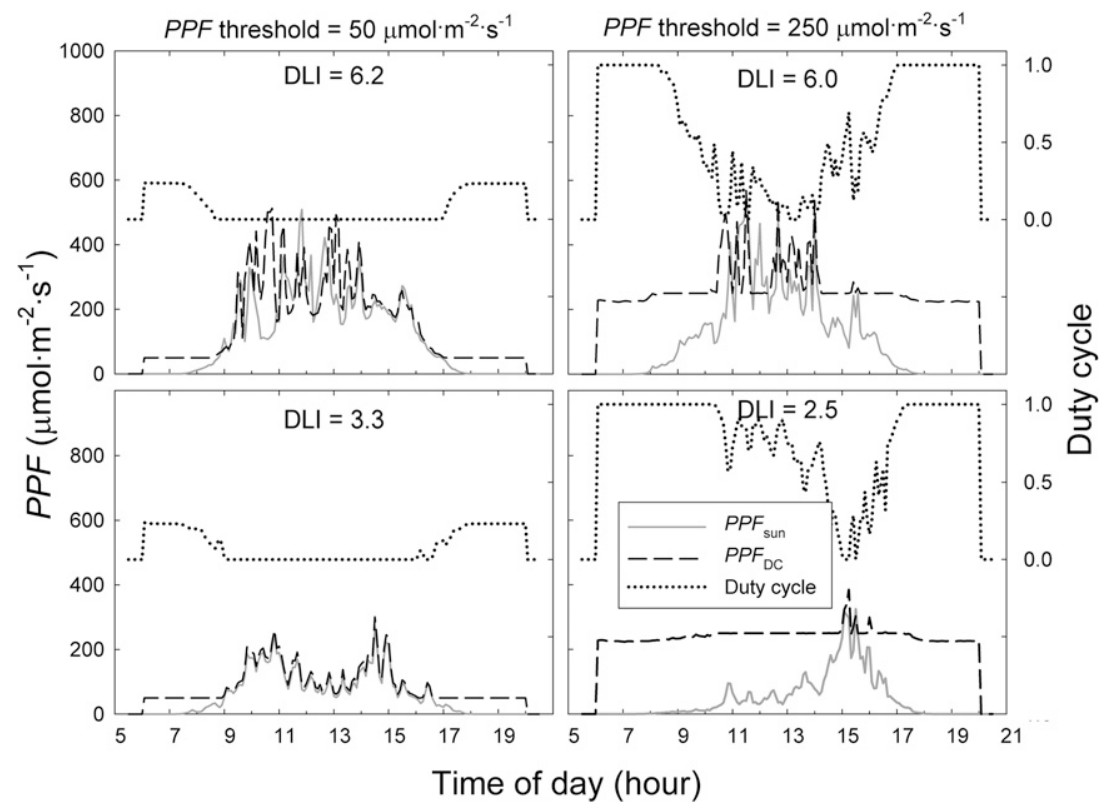

Fig. 2. Representative data of the performance of the adaptive light-emitted diode (LED) light control system. The system controls the duty cycle of the LED light in such a way that the LED grow light provides just enough light so that the combined photosynthetic photon flux $(P P F)$ from the sun and LED light reaches the $P P F$ threshold. Data shown are for the highest and lowest $P P F$ threshold on days with relatively low and high daily light integrals $\left(\mathrm{DLI}\right.$, in $\left.\mathrm{mol} \cdot \mathrm{m}^{-2} \cdot \mathrm{d}^{-1}\right)$. Note that the LED light bar could only provide a $P P F$ of $\approx 225 \mu \mathrm{mol} \cdot \mathrm{m}^{-2} \cdot \mathrm{s}^{-1}$. Therefore, the $250 \mu \mathrm{mol} \cdot \mathrm{m}^{-2} \cdot \mathrm{s}^{-1} P P F$ threshold was not reached when the $P P F$ from sunlight was below $25 \mu \mathrm{mol} \cdot \mathrm{m}^{-2} \cdot \mathrm{s}^{-1}$. 
period. That results in duty cycles $>0$, even though the average $P P F$ from sunlight is above the threshold value (Fig. 3).

Although controlling the LED bars by turning them on and off based on the $P P F$ from sunlight ( $P P F$ control) in principle worked well, it quickly became apparent that this control approach would not be practical in a commercial greenhouse setting. Whenever, the $P P F$ from sun is close to the target $P P F$, this control strategy can results in the LED light quickly and unpredictably being turned on and off. That in turn results in an adverse working environment. The results from this treatment are thus not described in detail.

Duty cycles and energy savings. Reductions in the duty cycle of the LEDs translate directly into energy and cost savings. To quantify the effects of different lighting strategies on electrical use, we calculated the average duty cycle for each 14-h supplemental light period and plotted these against the DLI provided by sunlight (Fig. 4). Since the control treatment had the LEDs on at full power for the entire 14-h period, the average duty cycle in this treatment was always 1 (results not shown). The average daily duty cycle in both the PWM and PPF control treatments depended on both the $\mathrm{DLI}_{\text {sun }}$ and threshold $P P F$. As the $\mathrm{DLI}_{\text {sun }}$ increased, less supplemental light was needed, and the average duty cycle decreased. Conversely, the average duty cycle increased with increasing PPF thresholds, because more supplemental light was needed to maintain the $P P F$ underneath the LED bars at those higher thresholds (Fig. 4).

Since PWM control of the LED lights only provided enough $P P F$ to reach the threshold value, whereas with $P P F$ control the lights were turned on at full power when supplemental light was needed, PWM control resulted in lower duty cycles. With PWM control, average daily duty cycles ranged from 0.80 on a day with a low $\mathrm{DLI}_{\text {sun }}$ of $2.52 \mathrm{~mol} \cdot \mathrm{m}^{-2} \cdot \mathrm{d}^{-1}$ and a $P P F$ threshold of $250 \mu \mathrm{mol} \cdot \mathrm{m}^{-2} \cdot \mathrm{s}^{-1}$, to 0.08 when the $\mathrm{DLI}_{\text {sun }}$ was $7.9 \mathrm{~mol} \cdot \mathrm{m}^{-2} \cdot \mathrm{d}^{-1}$ and the $P P F$ threshold was $50 \mu \mathrm{mol} \cdot \mathrm{m}^{-2} \cdot \mathrm{s}^{-1}$. In contrast, with $P P F$ control of the light bar, the average daily duty cycle ranged from 1.0 (always on) when the $\mathrm{DLI}_{\text {sun }}$ was $2.8 \mathrm{~mol} \cdot \mathrm{m}^{-2} \cdot \mathrm{d}^{-1}$ and the $P P F$ threshold was $200 \mu \mathrm{mol} \cdot \mathrm{m}^{-2} \cdot \mathrm{s}^{-1}$, to 0.41 on a day with a $P P F$ threshold of $50 \mu \mathrm{mol} \cdot \mathrm{m}^{-2} \cdot \mathrm{s}^{-1}$ and a DLI sun $_{\text {of }} 7.9 \mathrm{~mol} \cdot \mathrm{m}^{-2} \cdot \mathrm{d}^{-1}$.

DLIs with different control methods. As expected, the control treatment, where the LED lights were on at full power for $14 \mathrm{~h} \cdot \mathrm{d}^{-1}$, resulted in the highest DLI underneath the LED light. Having the LEDs on for $14 \mathrm{~h} \cdot \mathrm{d}^{-1}$ (i.e., average duty cycle of 1) increased the DLI by $13.5 \mathrm{~mol} \cdot \mathrm{m}^{-2} \cdot \mathrm{d}^{-1}$, regardless of the $\mathrm{DLI}_{\text {sun }}$ (Fig. 5). The $P P F$ control approach provided $\approx 7$ to $13 \mathrm{~mol} \cdot \mathrm{m}^{-2} \cdot \mathrm{d}^{-1}$ of supplemental DLI, depending on the $P P F$ threshold and the $\mathrm{DLI}_{\text {sun }}$. The most supplemental light was provided on days with very low $\mathrm{DLI}_{\text {sun }}$, which is consistent with high average daily duty cycles on those days (Fig. 4). The PWM control resulted in the lowest supplemental light levels, ranging from $\approx 1.7$ to 9.7

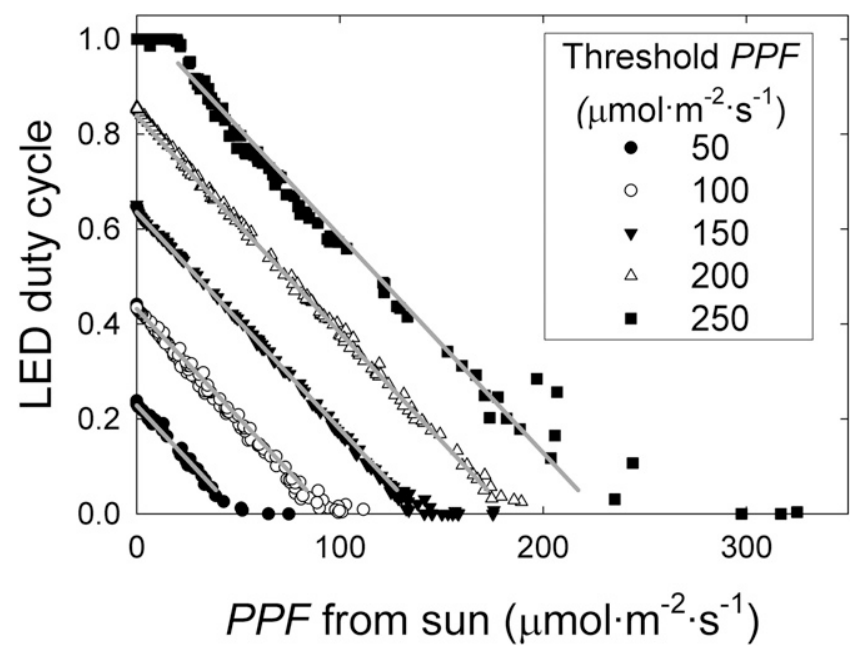

Fig. 3. The relationship between the duty cycle of the light-emitted diode (LED) light and the photosynthetic photon flux $(P P F)$ provided by sunlight (left). The duty cycle was adjusted every second so that the LED light bar provided just enough supplemental light to assure that the total amount of $P P F$ underneath the light bar reached the threshold level. Each data point is the average of 300 measurements collected over 5-min intervals. Using data points with duty cycles from 0.05 to 0.95 : Duty cycle $=0.0250-\left(0.00457 \times P P F_{\text {sun }}\right)+\left(0.00407 \times P P F_{\text {threshold }}\right), R^{2}=0.99$.
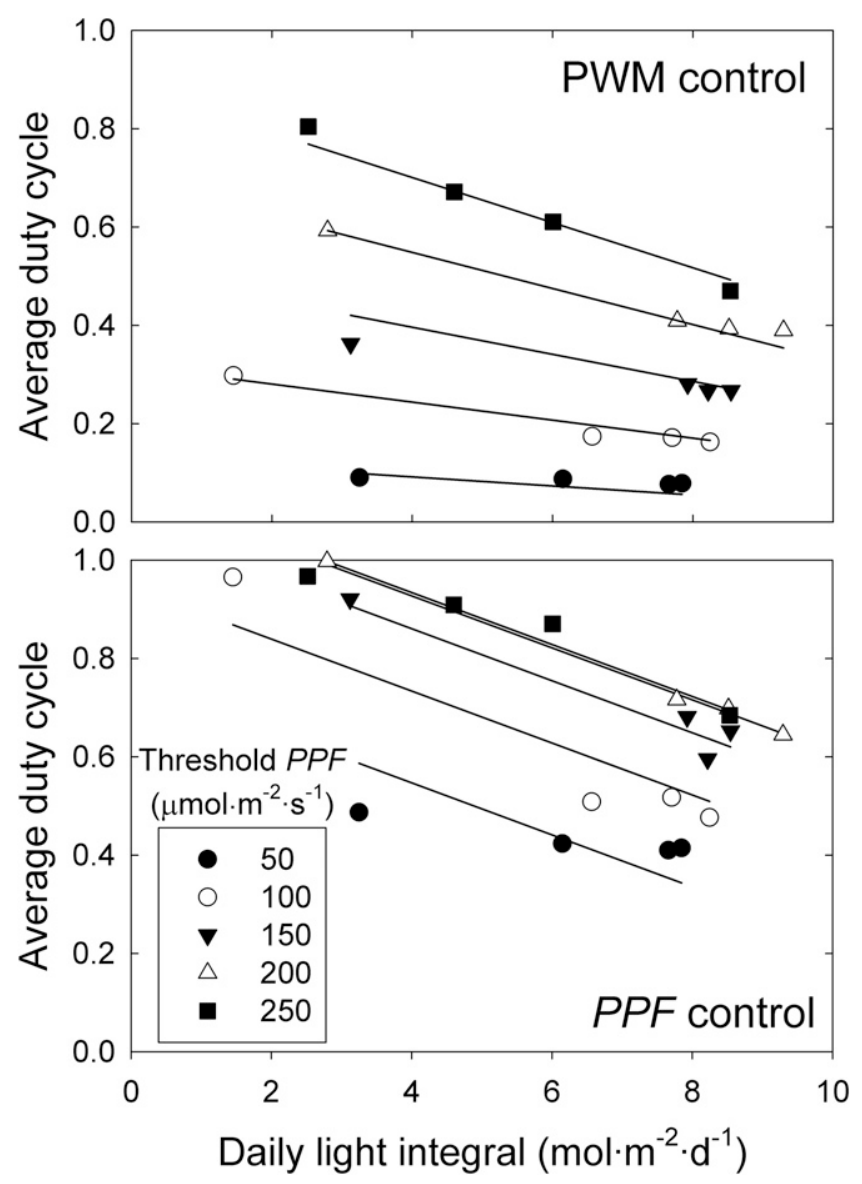

Fig. 4. The average duty cycle of light-emitted diode (LED) lights over a 14-h photoperiod as a function of the daily light integral from sunlight $\left(\mathrm{DLI}_{\text {sun }}\right)$ on that day. Two different approaches to lighting control were tested. Pulse width modulation (PWM) control (top) refers to adjustments made in the duty cycle of the LEDs to provide just enough light to reach the threshold photosynthetic photon flux $(P P F)$. With $P P F$ control, the LEDs are turned on at full power every time the $P P F$ from sunlight drops below the threshold $P P F$. Regression lines were derived from the following equations: for PWM control, Duty cycle $=-0.0604+0.00378 \times$ threshold $P P F-0.000184 \times \mathrm{DLI}_{\text {sun }} \times$ threshold $P P F, R^{2}=0.99$; for $P P F$ control: Duty cycle $=0.512+0.00553 \times$ threshold $P P F-0.0000120 \times$ threshold $P P F^{2}-0.0529 \times$ $\mathrm{DLI}_{\text {sun }}\left(R^{2}=0.98\right)$. 
$\mathrm{mol} \cdot \mathrm{m}^{-2} \cdot \mathrm{d}^{-1}$, depending on $P P F$ threshold and $\mathrm{DLI}_{\text {sun }}$ (Fig. 5).

The DLI underneath the lights, combined for all three lighting control methods, could be accurately described as a function of the $\mathrm{DLI}_{\text {sun }}$ and the average duty cycle over the 14-hr photoperiod ( $R^{2}=0.98$, Fig. 5$)$, without an interactive effect between the duty cycle and sunlight. This illustrates that the adaptive lighting control method does not provide additional $P P F$ more efficiently; instead, it provides additional light specifically when ambient $P P F$ is low.

Supplemental light and photosynthesis. To illustrate the potential benefits of adaptive, PWM control of LED lights, we simulated the increase in $\mathrm{A}_{\mathrm{n}}$ of $H$. americana and C. portenschlagiana as a result of supplemental light in the presence of different intensities of $P P F$ from sunlight (Fig. 6). Increasing amounts of supplemental $P P F$ increase $A_{n}$ nonlinearly: the more supplemental light is provided, the less efficiently it increases $A_{n}$. This response was more pronounced for $H$. americana than for $C$. portenschlagiana. For example, in the absence of sunlight, $50 \mu \mathrm{mol} \cdot \mathrm{m}^{-2} \cdot \mathrm{s}^{-1}$ of supplemental light increases simulated $\mathrm{A}_{\mathrm{n}}$ of $H$. americana and $C$. portenschlagiana by 4.4 and 3.0 $\mu \mathrm{mol} \cdot \mathrm{m}^{-2} \cdot \mathrm{s}^{-1}$, respectively, so the expected increase in $A_{n}$ is $47 \%$ greater for $H$. americana. However, if $250 \mu \mathrm{mol} \cdot \mathrm{m}^{-2} \cdot \mathrm{s}^{-1}$ of supplemental light is provided with no ambient light, $H$. americana would be expected to have an $\mathrm{A}_{\mathrm{n}}$ of $9.8 \mu \mathrm{mol} \cdot \mathrm{m}^{-2} \cdot \mathrm{s}^{-1}, 17 \%$ less than the $\mathrm{A}_{\mathrm{n}}$ of 11.8 $\mu \mathrm{mol} \cdot \mathrm{m}^{-2} \cdot \mathrm{s}^{-1}$ of $C$. portenschlagiana. Providing 50 to $250 \mu \mathrm{mol} \cdot \mathrm{m}^{-2} \cdot \mathrm{s}^{-1}$ of supplemental light with a background $P P F$ from sunlight of $250 \mu \mathrm{mol} \cdot \mathrm{m}^{-2} \cdot \mathrm{s}^{-1}$ is expected to increase $A_{n}$ of $H$. americana by only 0.29 to $0.64 \mu \mathrm{mol} \cdot \mathrm{m}^{-2}$ $\cdot \mathrm{s}^{-1} \cdot \mathrm{A}_{\mathrm{n}}$ of $C$. portenschlagiana on the other hand would be expected to increase by 1.6 to $6.1 \mu \mathrm{mol} \cdot \mathrm{m}^{-2} \cdot \mathrm{s}^{-1}$ (Fig. 6).

\section{Discussion}

Three different supplemental lighting methods were compared, $14 \mathrm{~h} \cdot \mathrm{d}^{-1}$ of supplemental light at full power, turning on the supplemental light at full power only when ambient $P P F$ was below a specific threshold, and providing just enough supplemental light to reach a specific $P P F$ threshold. Turning the LED grow lights on and off based on ambient light levels was deemed to be nonpractical, because it can result in the LEDs turning on and off frequently, which would result in a difficult working environment. The adaptive PWM control of supplemental lighting, on the other hand, makes constant, small adjustments in supplemental lighting to maintain a stable $P P F$ at the crop level. Since the PWM control does not result in large, sudden changes in $P P F$, it would not have a negative impact on the working environment inside a greenhouse. The required duty cycle of the LED grow lights could be described based on a simple linear function of sunlight $P P F$ and the threshold $P P F$ (Fig. 3). The relatively simple relationship between the $P P F$ from sunlight and the duty

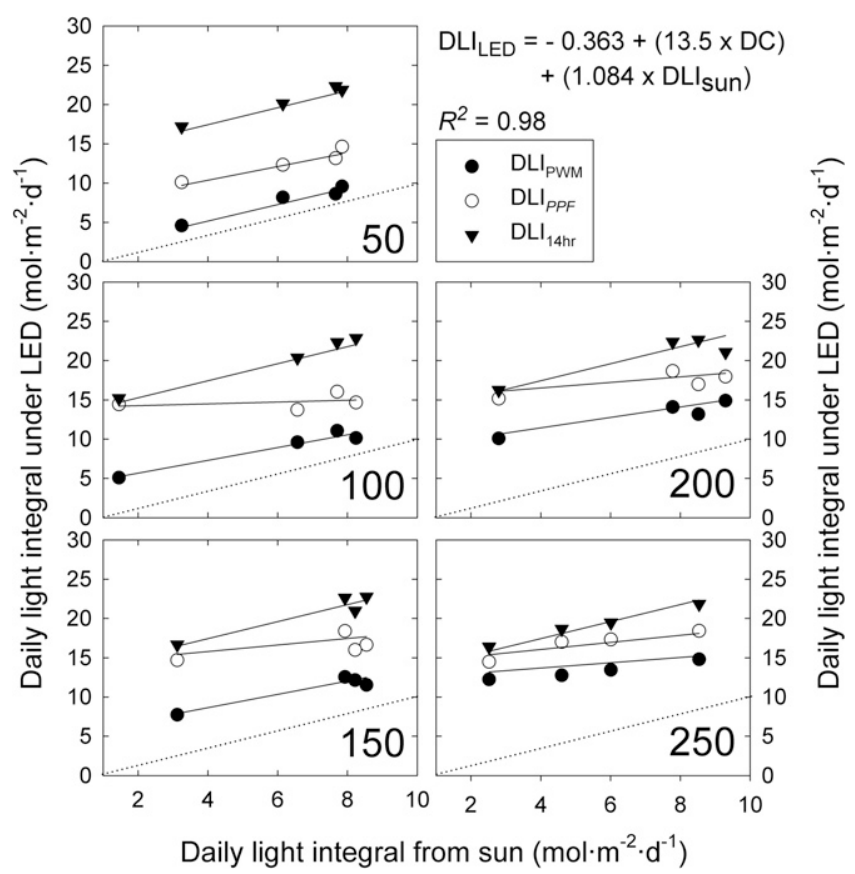

Fig. 5. The daily light integral measured underneath light-emitted diode (LED) light bars that were controlled in one of three ways: 1) 14-hr of supplemental light with the LEDs on at full power (DLI ${ }_{14 h r}$ ), 2) LEDs were turned on at full power whenever the photosynthetic photon flux $(P P F)$ from sunlight dropped below the threshold $P P F$ (DLI $\mathrm{I}_{\mathrm{PPF}}$ ), and 3) pulse-width modulation control in which the duty cycle of the LED bar was adjusted every second to provide just enough supplemental light to reach the threshold $P P F\left(\mathrm{DLI}_{\mathrm{PWM}}\right.$ ). Numbers in the lower right corner of the graphs indicate the threshold $P P F$ (in $\mu \mathrm{mol} \cdot \mathrm{m}^{-2} \cdot \mathrm{s}^{-1}$ ). Lines shown were calculated using the multiple regression equation (upper right).
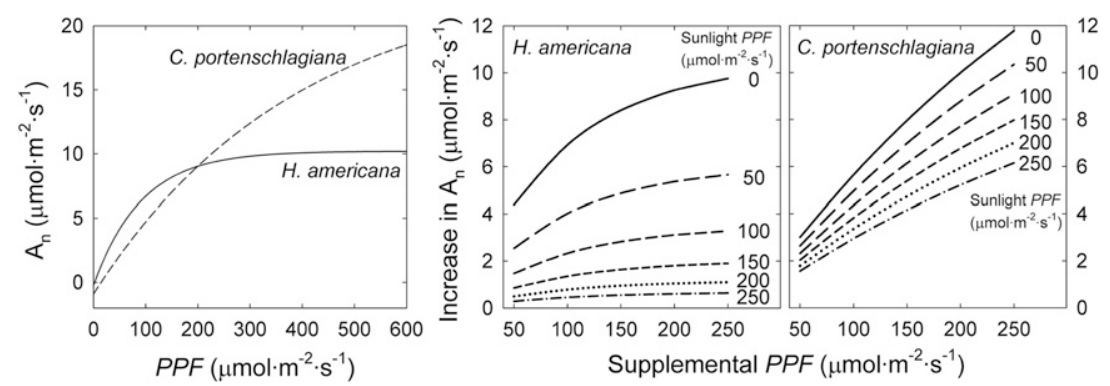

Fig. 6. Photosynthesis $\left(\mathrm{A}_{\mathrm{n}}\right)$-light response curve for Heuchera americana 'Dale's Strain' grown at an average daily light integral of $7.8 \mathrm{~mol} \cdot \mathrm{m}^{-2} \cdot \mathrm{d}^{-1}$ and ambient $\mathrm{CO}_{2}$ (data from Garland et al., 2012) and Campanula portenschlagiana 'Blue Get Mee' grown under long days and elevated $\mathrm{CO}_{2}(600$ $\mu \mathrm{mol} \cdot \mathrm{mol}^{-1}$; Kjaer et al., 2011). Regression curves: H. americana $\mathrm{A}_{\mathrm{n}}=-0.24+10.4 \times\left(1-\mathrm{e}^{-0.011 \times P P F}\right)$, C. portenschlagiana $\mathrm{A}_{\mathrm{n}}=-0.91+24.6 \times\left(1-\mathrm{e}^{-0.026 \times P P F}\right), R^{2}>0.98$ for both species. These curves were used to estimate the increase in $A_{n}$ of both species that can be achieved by providing supplemental light in the presence of different amounts of photosynthetic photon flux $(P P F)$ provided by sunlight.

cycle of the LEDs opens the door to a simplified approach to adaptive lighting control: if the $P P F$ from sunlight is measured and the supplemental $P P F$ from the LED light at full power is known, the required duty cycle to reach a specific $P P F$ level underneath the LED light can be calculated as (threshold $P P F-P P F$ from sun $) /(P P F$ from LED at full power). Using regression analysis of the data from Fig. 3 with duty cycles from 0.05 to 0.95 , the required duty cycle to achieve a specific threshold $P P F$ is $4.22 \times 10^{-3} \times$ (threshold $P P F-P P F$ from sun) $\left(R^{2}=0.99\right)$.

The adaptive, PWM approach to controlling supplemental lighting differs significantly from the previous approaches.
Albright et al. (2000) focused on achieving a specific DLI, whereas PWM control provides supplemental light based on instantaneous ambient $P P F$. Energy savings resulting from PWM, as evidenced by the daily average duty cycle, ranged from $20 \%$ to $92 \%$, depending on the DLI $\mathrm{I}_{\text {sun }}$ and threshold PPF (Fig. 4). Such savings in energy may not be useful if those reductions in energy use result in equivalent reductions in photosynthesis. However, adjusting supplemental $P P F$ based on ambient $P P F$ assures that the supplemental light is provided when that supplemental light can be used most efficiently by the crop, that is, when ambient $P P F$ is low (Fig. 6). Because there are differences among species 
in how their $A_{n}$ responds to supplemental light, crop specific information may be needed to get the maximum benefit from supplemental lighting. Although our simulation results only apply to $H$. americana and $C$. portenschlagiana grown under these specific conditions, the $\mathrm{A}_{\mathrm{n}}$ responses to $P P F$ of these two species illustrate important points about supplemental lighting in general. Because of the non-linear relationship between $P P F$ and $\mathrm{A}_{\mathrm{n}}$, supplemental light increases $A_{n}$ most efficiently when: 1) it is provided when ambient $P P F$ is low and 2) when the amount of supplemental $P P F$ is relatively low. In addition, because $A_{n}$ $P P F$ response curves differ among species (Fig. 6), optimal supplemental lighting strategies are crop specific.

If desired, the PWM control system could keep track of the accumulated $P P F$ over the course of a day and be programmed to provide enough supplemental PPF over the course of a day to reach a specific DLI. Alternatively, the PWM control system could be combined with crop-specific $\mathrm{A}_{\mathrm{n}}-P P F$ response curves (e.g., Fig. 6) to estimate leaf $A_{n}$ at the top of canopy. By integrating $A_{n}$ over the course of a day, a daily photosynthetic integral can be calculated. In principle, a PWM control system can be programmed to assure that a particular daily photosynthetic integral is reached, similar to the approach by Kjaer et al. (2011) and Clausen et al. (2015). The challenge of implementing such an approach is the development of simple methods to quickly determine crop-specific $\mathrm{A}_{\mathrm{n}}$ - PPF response curves. Photosynthetic responses to different light levels are species specific and can depend on the growing conditions, because plants may acclimate to their environment and this ability to acclimate is species-dependent (Demmig-Adams et al., 2012). For example, Begonia semperflorenscultorum has a higher dark respiration rate, maximum gross leaf photosynthetic rate, and light compensation point when grown under higher DLI (Nemali and van Iersel, 2004), whereas $H$. americana does not appear to show such acclimation (Garland et al., 2012).

Unlike other lighting control approaches (Albright et al., 2000; Clausen et al., 2015; Heuvelink and Challa, 1989), our control approach does not take into account weather (other than instantaneous $P P F$ ), climatic data, crop value, or the real-time cost of electricity. That has both advantages and disadvantages: PWM control of LED grow lights is easy and cheap to implement and does not depend on external information. That makes it relatively easy to develop simple, stand-alone controllers for LED lights. However, real-time information of electricity costs (or possibly a database with information on short- and long-term patterns in electricity prices) can undoubtedly improve the cost effectiveness of lighting control by preferentially providing supplemental lighting when electricity prices are relatively low. That said, the simulation results of the effects of supplemental lighting on $\mathrm{A}_{\mathrm{n}}$ of $H$. americana shows the importance of providing supplemental light when ambient $P P F$ is low. Thus, a more advanced control system for supplemental light may need to take into account crop-specific $A_{n}$
- $P P F$ response curves, ambient $P P F$, crop value, and fluctuations in electricity prices. In addition, it is important to account for any specific photoperiod requirements of the crop to assure that flowering is not induced prematurely or delayed unnecessarily.

Although our focus was to develop a control system for LED grow lights to make supplemental lighting more cost effective in commercial greenhouse production, this approach can also have benefits for research. A PWM-based control system can be used for testing precisely controlled, different lighting treatments, as well as for minimizing spatial and temporal variability in $P P F$ that can negatively impact experiments. For example, in the case of a greenhouse with spatial differences in $P P F$, PWM control of supplemental light can assure that plants in different parts of a greenhouse receive similar $P P F$. Likewise, PWM control of lighting can be used to minimize the effect of seasonal variability in light levels, by maintaining specific minimum $P P F$ levels year round.

\section{Conclusions}

Adjusting the duty cycle of LED grow lights can accurately maintain $P P F$ at the canopy level by only providing supplemental light when needed and only at the intensity needed to reach a specific threshold $P P F$. This approach to supplemental lighting control can be used to assure that supplemental light is provided when it can be used most efficiently by the crop. By taking advantage of the controllability of LED lights, PWM control can help make supplemental lighting more cost effective. This approach to controlling supplemental lighting can reduce the cost of supplemental lighting in commercial greenhouses and can reduce short- and long-term variability in research greenhouses, where $P P F$ often is poorly controlled, if at all.

\section{Literature Cited}

Albright, L.D., A.J. Both, and A.J. Chiu. 2000. Controlling greenhouse light to a consistent daily integral. Trans. ASAE 43:421-431.

Bot, G.P.A. 2001. Developments in indoor sustainable plant production with emphasis on energy saving. Comput. Electron. Agr. 30:151-165.

Bourget, C.M. 2008. An introduction to lightemitting diodes. HortScience 43:1944-1946.

Clausen, A., H.M. Maersk-Moeller, J. Corfixen Soerensen, B.N. Joergensen, K.H. Kjaer, and C.O. Ottosen. 2015. Integrating commercial greenhouses in the smart grid with demand response based control of supplemental lighting, p. 199-213. In: Intl. Conf. Ind. Technol. Mgt. Sci. (ITMS 2015).

Demmig-Adams, B., C.M. Cohu, O. Muller, and W.W. Adams. 2012. Modulation of photosynthetic energy conversion efficiency in nature: From seconds to seasons. Photosynth. Res. 113:75-88.

Garland, K.F., S.E. Burnett, M.E. Day, and M.W. van Iersel. 2012. Influence of substrate water content and daily light integral on photosynthesis, water use efficiency, and morphology of Heuchera americana. J. Amer. Soc. Hort. Sci. 137:57-67.

Gómez, C., R.C. Morrow, C.M. Bourget, G.D. Massa, and C.A. Mitchell. 2013. Comparison of intracanopy light-emitting diode towers and overhead high-pressure sodium lamps for supplemental lighting of greenhousegrown tomatoes. HortTechnology 23:93-98.

Goto, E. 2012. Plant production in a closed plant factory with artificial lighting. Acta Hort. 956:37-49.

Heuvelink, E.P. and H. Challa. 1989. Dynamic optimization of artificial lighting in greenhouses. Acta Hort. 260:401-412.

Jensen, M.H. and A.J. Malter. 1995. Protected agriculture: A global review. World Bank technical paper; no. WTP 253. The World Bank, Washington, DC.

Kjaer, K.H., C.O. Ottosen, and B.N. Jørgensen. 2011. Cost-efficient light control for production of two campanula species. Sci. Hort. 129:825-831

Korczynski, P.C., J. Logan, and J.E. Faust. 2002. Mapping monthly distribution of daily light integrals across the contiguous United States. HortTechnology 12:12-16.

Liu, W. 2012. Light environment management for artificial protected horticulture. Agrotechnology 1, doi: 10.4172/2168-9881.1000101.

Morrow, R.C. 2008. LED lighting in horticulture. HortScience 43:1947-1950.

Nelson, J.A. and B. Bugbee. 2014. Economic analysis of greenhouse lighting: Light emitting diodes vs. high intensity discharge fixtures. PLoS One 9:e99010.

Nelson, P.V. 2003. Greenhouse operation and management. 6th ed. Prentice Hall, Upper Saddle River, NJ.

Nemali, K.S. and M.W. van Iersel. 2004. Acclimation of wax begonia to light intensity: Changes in photosynthesis, respiration, and chlorophyll concentration. J. Amer. Soc. Hort. Sci. 129:745-751.

Ouzounis, T., E. Rosenqvist, and C.-O. Ottosen. 2015. Spectral effects of artificial light on plant physiology and secondary metabolism: A review. HortScience 50:1128-1135.

Pimputkar, S., J.S. Speck, S.P. DenBaars, and S. Nakamura. 2009. Prospects for LED lighting. Nat. Photonics 3:180-182.

PLOS ONE. 2016. New LED fixtures from Philips with efficacies of 1.9 to 2.46 micromol per joule. 9 Sept. 2016. <http://journals. plos.org/plosone/article/comment?id=info $\%$ 3Adoi/10.1371/annotation/a162bf97-4868-40b9$86 \mathrm{c} 0-\mathrm{f} 390 \mathrm{c} 2 \mathrm{aac} 055>$.

Stutte, G.W. 2015. Commercial transition to LEDs: A pathway to high-value products. HortScience 50:1297-1300.

Tennessen, D.J., R.J. Bula, and T.D. Sharkey. 1995. Efficiency of photosynthesis in continuous and pulsed light emitting diode irradiation. Photosynth. Res. 44:261-269.

U.S. Department of Agriculture National Agricultural Statistics Service. 2014. 2012 Census of agriculture. United States summary and state data.

Utah State University. 2016. NCERA-101 Instrument package. 9 Sept. 2016. <https://cpl.usu. edu/htm/ncera-101-package>.

van Iersel, M.W., M. Chappell, and J.D. Lea-Cox 2013. Sensors for improved efficiency of irrigation in greenhouse and nursery production. HortTechnology 23:723-735.

Vox, G., M. Teitel, A. Pardossi, A. Minuto, F. Tinivella, and E. Schettini. 2010. Sustainable greenhouse systems, p. 1-80. In: A. Salazar and I. Rios (eds.). Sustainable agriculture: Technology, planning and management. Nova, NY.

Wallace, C. and A.J. Both. 2016. Evaluating operating characteristics of light sources for horticultural applications. Acta Hort. 1134:435-444.

Woods, M. and A.S. Warren. 1988. Glass houses: A history of greenhouses, orangeries and conservatories. Rizzoli, NY. 